\title{
Book Review Editor's Farewell
}

This issue concludes my nine-year tenure as Associate Editor for Book Reviews. My deepest thanks go to the Quarterly for this opportunity.

Thanks and kudos go especially to the 406 book reviewers who penned 632 book reviews and 31 essay reviews in these nine volumes (concluding with two issues yet to appear). It has been my honor and privilege to commission, read, and correspond with you about your insightful reviews of new work and your scholarly assessments of trends over time in our literature. No one could ask for a more talented, accessible, and rewardingto-work-with roster of contributors than we have enjoyed with our book and essay reviewers. You are beginning scholars through senior professors, you reside on multiple continents, and you represent a rich range of academic, cultural, and personal perspectives. Your work has comprised approximately half of our journal's pages. Readers tell us that they often turn first to the book reviews. I trust they have not been disappointed! Thank you.

Many of the core leaders of this journal have moved from acquaintances to colleagues to friends of mine since I joined the History of Education Society in 1987. Richard J. Altenbaugh is an extraordinary individual whose talents and wisdom are equaled only by his deep sense of ethics, professionalism, and personal commitment. May everyone have the honor of working for and with such a person. Barbara Beatty and Linda Eisenmann, longtime Associate Editor colleagues, have been wonderful mentors and collaborators for many of these years, and great friends and supporters of this journal. It was on Bruce C. Nelson's broad and steady shoulders that so much of the content and administration of this journal has depended, as well as the journal's values and spirit. It was Bruce's headquarters office, and it was a great place to work and learn. Laurie Moses Hines, onetime $H E Q$ staffer in the Indiana University-Bloomington days, graced us with her presence and skillful development of the "Briefly Noted" section over the past three years. Many other HES colleagues have been so helpful, with the journal and as friends and mentors, over the years. It would be a long list. Finally, I want to thank the principal Book Review Editor under the Editorship that preceded us-Ronald Cohen at Indiana University Northwest-for setting the standard I tried to emulate and then maintain: a book review section broadly conceived to encompass a wide range of historical and cultural angles, from biography, to school architecture, to politics, to race and gender and family, and all the way to cartoons-and lots in between. Our field 
speaks, and listens, to educational history and culture, broadly defined. May it always be so.

Sincerely,

Robert A. Levin 